\title{
Zebrafish as a Model for the Study of Chaperonopathies
}

\author{
GIANFRANCO BELLIPANNI, ${ }^{1,2,3 *}$ FRANCESCO CAPPELLO, ${ }^{2,3,4 * *}$ FEDERICA SCALIA, ${ }^{4}$ \\ EVERLY CONWAY DE MACARIO,, ALBERTO J.L. MACARIO,,5 AND ANTONIO GIORDANO ${ }^{1,2}$
}

'Sbarro Institute for Cancer Research and Molecular Medicine, Philadelphia, Pennsylvania

${ }^{2}$ Department of Biology, College of Science and Technology, Temple University, Philadelphia, Pennsylvania

${ }^{3}$ Euro-Mediterranean Institute of Science and Technology (IEMEST), Palermo, Italy

${ }^{4}$ Department of Experimental Biomedicine and Clinical Neuroscience, University of Palermo, Palermo, Italy

${ }^{5}$ Department of Microbiology and Immunology, School of Medicine, University of Maryland at Baltimore and IMET, Baltimore, Maryland

\begin{abstract}
There is considerable information on the clinical manifestations and mode of inheritance for many genetic chaperonopathies but little is known on the molecular mechanisms underlying the cell and tissue abnormalities that characterize them. This scarcity of knowledge is mostly due to the lack of appropriate animal models that mimic closely the human molecular, cellular, and histological characteristics. In this article we introduce zebrafish as a suitable model to study molecular and cellular mechanisms pertaining to human chaperonopathies. Genetic chaperonopathies manifest themselves from very early in life so it is necessary to examine the impact of mutant chaperone genes during development, starting with fertilization and proceeding throughout the entire ontogenetic process. Zebrafish is amenable to such developmental analysis as well as studies during adulthood. In addition, the zebrafish genome contains a wide range of genes encoding proteins similar to those that form the chaperoning system of humans. This, together with the availability of techniques for genetic manipulations and for examination of all stages of development, makes zebrafish the organism of choice for the analysis of the molecular features and pathogenic mechanisms pertaining to human chaperonopathies.
\end{abstract}

J. Cell. Physiol. 231: 2107-21 14, 2016. (C) 2016 Wiley Periodicals, Inc.

\section{The Chaperoning System and Its Alterations}

Molecular chaperones, many of which are heat-shock proteins (Hsp), are widespread protein molecules typically involved in protein homeostasis (Ellis, 1996). They play a variety of roles: (I) canonical, which pertain to maintenance of protein homeostasis, and include assisting folding of nascent polypeptides, protecting proteins from denaturing stressors, promoting degradation of irreversibly misfolded or aggregated proteins, and facilitating protein translocation across membranes; and (2) non-canonical, which include participation in a variety of cellular phenomena unrelated to protein homeostasis. The new concepts of chaperoning system (the whole complement of molecular chaperones, both intra- and extracellular, of an organism), chaperonopathies (diseases due to impairment of chaperone functions), and chaperonotherapy (a novel way to treat human diseases by the restoring of functioning chaperones as well as their use as drugs or vaccines) have recently been reviewed (Macario et al., 2013).

In brief, malfunctioning of the chaperoning system, due to an impairment of one or more of its components, can cause diseases, the chaperonopathies, including pathologies affecting nervous, cardiovascular, respiratory, gastrointestinal, and other physiological systems. A chaperonopathy can be due to a structural defect in the chaperone molecule, or to mechanisms in which the affected chaperones are structurally normal but do not work properly, or work abnormally, or work to the advantage of the disease (Macario and Conway de Macario, 2005).

Chaperonopathies from an etiological point of view may be sorted out into genetic or acquired, while from a pathogenic standpoint can be classified into "by defect," "by excess," or "by mistake" (the latter also called "by collaborationism") categories (Table I). In the chaperonopathies by mistake, chaperones are not necessarily decreased or increased in quantity, or structurally abnormal (as much as it can be determined with the limited means available today to study protein molecules directly, in the cell) but they work to the advantage of the disease (e.g., cancer or autoimmune diseases) rather than protecting the host. In all these situations, the affected chaperone is the etiological-pathogenic factor, or at least a determinant secondary etiologic factor, necessary to cause a pathologic condition.

Since long time ago, the use of chaperones as targets or agents for therapeutics has been reported by many authors but, recently, the concept has been defined more precisely as chaperonotherapy and extended to include various modalities (Macario and Conway de Macario, 2007; Almeida et al., 20I I; Kondoh and Osada, 20 I3; Aguilà et al., 20 I4; Reddy and Reddy, 2015). For example, positive chaperonotherapy, in which a

Gianfranco Bellipanni and Francesco Cappello contributed equally to this work.

*Correspondence to: Gianfranco Bellipanni, Department of Biology, College of Science and Technology, Temple University, Philadelphia, PA 19122. E-mail: bellipa4@temple.edu

**Correspondence to: Francesco Cappello, Department of Experimental Biomedicine and Clinical Neuroscience, University of Palermo, Palermo, Italy. E-mail: francapp@hotmail.com

Manuscript Received: 22 January 2016 Manuscript Accepted: 25 January 2016

Accepted manuscript online in Wiley Online Library (wileyonlinelibrary.com): 27 January 2016.

DOI: $10.1002 /$ jcp. 25319 
TABLE I. Classification of chaperonopathies according to their pathogenic mechanism

\begin{tabular}{ll}
\hline Chaperonopathies & \multicolumn{1}{c}{ Mechanism, features } \\
\hline By excess & $\begin{array}{c}\text { Quantitative, for example, due to gene dysregulation } \\
\text { and overexpression; post-transcriptional } \\
\text { mechanisms } \\
\text { Qualitative, for example, gain of function } \\
\text { Quantitative, for example, gene downregulation; } \\
\text { post-transcriptional mechanisms } \\
\text { Qualitative, for example, due to structural defect } \\
\text { genetic or acquired }\end{array}$ \\
$\begin{array}{l}\text { Normal chaperones contribute to disease, for } \\
\text { example, some tumors that need chaperones to } \\
\text { By mistake or } \\
\text { collaborationism }\end{array}$ & $\begin{array}{l}\text { grow, and some autoimmune conditions in which a } \\
\text { chaperone is the autoantigen }\end{array}$ \\
\hline
\end{tabular}

Modified from: Macario AJL, Conway de Macario E, Cappello F. 2013. The Chaperonopathies. Diseases with defective molecular chaperones. New York London: Springer Dordrecht Heidelberg.

chaperone gene, or protein, is utilized to replace a malfunctioning chaperone, as it would be the case of chaperonopathies by defect caused by mutation of a chaperone gene. Alternatively, negative chaperonotherapy, would be applicable in cases of chaperonopathies by excess or by mistake, when it is necessary to block or eliminate a chaperone that is promoting disease.

Many chaperones are heat shock proteins (Hsps), but many others are not. However the use of the terms "Hsp" and "chaperone" indiscriminately in the literature and databases has made a distinction between them very difficult or at least impractical. This is why we will use both terms interchangeably in this review.

\section{Classification of Human Chaperonopathies}

Chaperones can be classified in several ways, but one which is commonly used by physicians and pathologists is based on molecular weight, Table 2 , and as far as nomenclature is concerned, there are in the literature and databases a variety of names for each chaperone gene and protein, which is confusing. To alleviate this situation a nomenclature system has recently been proposed based largely on the HUGO Gene Nomenclature Committee and the National Center of Biotechnology Information Entrez Gene databases (Kampinga et al., 2009).

As shown in Table 2, the classification of chaperones includes families of phylogenetically related proteins, for example, the Hsp90, Hsp70, Hsp60, Hsp40, and the small Hsp (sHsps) families. Other members of these groups are not part of those families although they have molecular weights within the stipulated ranges. Chaperonopathies involve chaperones pertaining to all these groups.

Mutations in chaperone genes have been found associated with diseases and syndromes affecting one or more of the various physiological systems, for example the nervous system, as illustrated by hereditary chaperonopathies due to Hsp60 mutations, Table 3. Diseases associated with mutations in the genes encoding proteins within the $\mathrm{Hsp} 70$ and $\mathrm{Hsp} 40$ families are shown in Table 4. The chaperonopathies associated with defects in members of the sHsp group are shown in Table 5. Surprisingly, there are no known chaperonopathies due to a mutation in the genes encoding Hsp90. A number of nongenetic pathologic conditions due to chaperone malfunction or collaborationism have been described. They may be divided into these main groups:

(I) Sepsis, fever, fatigue: these are pathological conditions in which the levels of Hsps may be increased and they contribute to disease initiation-progression (Essig and Nosek, 1997; Singh and Hasday, 20I3).
(2) Cancer: there are a number of neoplasms in which Hsps promote tumor-cell growth by various mechanisms, including blockage of the apoptotic cascade and escape from immune surveillance (Joly et al., 20I0; Rappa et al., 20I2). These are conditions in which Hsps "collaborate" with the disease rather than with the host.

(3) Autoimmune conditions: since Hsps are evolutionarily very conserved and, therefore, very similar across species, the bacterial counterparts of some human Hsps can induce antibodies against themselves and these antibodies are crossreactive with the human equivalents. By this mechanism, known as molecular mimicry (Cappello et al., 2009; Rajaiah and Moudgil, 2009), foreign Hsps can trigger initiation of autoimmune diseases. These conditions are considered chaperonopathies by mistake or collaborationism.

(4) Cardiovascular diseases: the pathogenesis of atherosclerosis and heart failure can involve chaperone malfunction. The former has been proposed as an autoimmune disease due to autoimmunity against Hsps (Wick et al., 20I4), while heart failure can be due to a dysregulation of a Hsp gene accompanied by the gain of a new, extrachaperoning, function of its protein product (Knowlton et al., 1998).

(5) Aging: this condition has been associated to a malfunction of molecular chaperones, for example, due to post-translational modifications that reduce their functionality. During aging, altered Hsps may reduce the efficacy or misdirect some functions of the immune system, which, during the rest of the life of a subject, can be abnormally modulated by aged extracellular Hsps (Macario et al., 2010).

(6) Neurodegenerative diseases: Hsps have been implicated in the pathogenesis of Alzheimer's disease and other forms of dementia; this pathogenic effect seems to be related, at least in some instances, to the impairment of the Hsps functions that occur during aging (Deture et al., 2010; Bolshette et al., 2014).

\section{Zebrafish as Animal Model for the Study of Chaperones} and Chaperonopathies

There is considerable information on the clinical manifestations of the chaperonopathies in general, and on the inheritance patterns of the genetic cases that have been studied in detail. However, there is very little information on the molecular features and mechanisms pertaining to chaperonopathies, genetic or acquired. Part of this lack of information is due to the scarcity of model systems amenable to the study of human chaperonopathies. A prokaryotic model has recently been used to elucidate some molecular aspects of a chaperonopathy caused by a mutation in the CCT subunit 5 (Min et al., 20I4). Nevertheless, eukaryotic models are still necessary and, in this article, we will discuss the potential of zebrafish as a convenient system for investigating molecular mechanisms pertinent to human chaperonopathies.

In the past 30 years, zebrafish has successfully scaled up the list of the best animal models to study conditions affecting humans (Kinth et al., 20I3). Initially, this simple vertebrate caught the attention of developmental biologists and geneticists because of its external fertilization; fast growth; transparency of the embryo and ease to apply classic embryological, biochemical, molecular biological techniques; and the use of rudimentary yet effective mutagenesis by irradiation (Grunwald et al., 1988). Later, thanks to its fast life cycle, inexpensive maintenance costs and the possibility of applying sing $N$-ethyl-N-nitrosourea (ENU) mutagenesis, zebrafish became widely used for forward genetic mutagenesis screens (Mullins and Nusslein-Volhard, 1993; Haffter et al., 1996). Once it was clear that many genes and biological mechanisms were 
TABLE 2. Classification of molecular chaperones according to their molecular weight: Some illustrative examples for each category

\begin{tabular}{|c|c|c|}
\hline $\begin{array}{l}\mathrm{MW}(\mathrm{kDa}) \\
\text { range }\end{array}$ & Classical family & Other members in this range implicated in the causation of chaperonopathies \\
\hline $\begin{array}{l}200 \text { or higher } \\
100-199\end{array}$ & $\begin{array}{c}\text { None } \\
\text { Hspl00-110 }\end{array}$ & Sacsin \\
\hline $81-99$ & Hsp90 & Paraplegin \\
\hline $65-80$ & $\mathrm{Hsp} 70$ & Spastin; LARP7 \\
\hline $55-64$ & $\begin{array}{c}\text { Hsp60 (groups I and II } \\
\text { chaperonins) }\end{array}$ & Myocilin; protein disulphide-isomerases \\
\hline $\begin{array}{l}35-54 \\
34 \text { or less }\end{array}$ & $\begin{array}{c}\text { Hsp40 } \\
\text { Small Hsp (sHSP): crystallins }\end{array}$ & $\begin{array}{l}\text { AIP; AIPLI; torsin A; clusterin; DNAJCI9 } \\
\text { Hsp I0; Alpha hemoglobin-Stabilizing Protein; cyclophilin type peptidyl-prolyl cis-trans isomerases; } \\
\text { alpha-synuclein; HSPBII }\end{array}$ \\
\hline
\end{tabular}

Modified from: Macario AJL, Conway de Macario E, Cappello F. 2013. The Chaperonopathies. Diseases with defective molecular chaperones. New York London: Springer Dordrecht Heidelberg.

conserved from the zebrafish to human, the use of the zebrafish animal model for modeling human diseases gained acceptance by many scientists.

Modeling of human diseases is now one of the preferred uses of zebrafish because it has become a common laboratory routine to knock-down genes via morpholinos (Nasevicius and Ekker, 2000), to create transgenic fish (Higashijima et al., 2000; Balciuniene et al., 20I3) and, to apply the more recently developed reverse genetic techniques to the fish (Jao et al., 20I3; Hwang et al., 20I3; Auer and Del Bene, 2014). Many studies are demonstrating still more similarities between human and zebrafish also at the cellular and organismal levels. In this regard, particularly revealing have been the studies on angiogenesis, cardiac development, and regeneration, function of the nervous system, and nociception and cancer (Nicoli et al., 2007; Siekmann and Lawson, 2007; Kikuchi and Poss, 20I2; Malafoglia et al., 20I3, 20I4; Yen et al., 20I4). Despite intrinsic metabolic differences in mammalian and fish species, lately zebrafish has been used for studying metabolism and modelling metabolic diseases (Seth et al., 2013). Moreover, in 2013 the whole zebrafish genome was completely sequenced (Howe et al., 2013) further supporting, at the genetic level, a plethora of previous studies that had already indicated the high degree of similarities between human and zebrafish. Finally, it has become evident that zebrafish is useful even if some of its peculiar characteristics are not shared with mammals, such as its ability to regenerate nerves as well as fins and heart tissue (Gemberling et al., 20I3). The high relevance for human health of such mechanisms made the zebrafish the centerpiece of research aiming to uncover the basis of tissue and nerve regeneration and, hopefully, to use it for developing new therapeutic approaches.

\section{Heat-Shock Proteins and Chaperone Genes in Zebrafish}

The analysis of the zebrafish genome and other molecular genetic studies have revealed a large set of genes encoding members of the chaperoning system, Table 6 , with extensive overlapping with that of humans. From these data, it becomes clear that zebrafish offers the possibility of modeling human genetic chaperonopathies because its genome has the homologs of the pertinent human genes.

Two decades ago the zebrafish animal model begun to be employed for studying the expression and function of a variety of genes in the vertebrates. This included the expression and function of the heat-shock genes. Despite the fact that zebrafish live in water and at temperatures ranging from $25^{\circ} \mathrm{C}$ to $33^{\circ} \mathrm{C}$, which are conditions different from those typical of the environment in which most mammals reside, they do show heat-shock response and express heat shock factors I and 2 (HSFI and 2) (Wang et al., 200 I). In addition to the heat shockinducible chaperone genes, many other genes not inducible by heat shock but nonetheless pertinent to the stress response are also expressed in the zebrafish, and many of them are expressed during embryogenesis. Some of the Hsp genes studied in zebrafish are individually discussed below.

\section{Hsp90}

Hsp90 is present in two isoforms, $a$ and $b$, in the zebrafish. While the $a$ isoform is heat inducible the $b$ isoform is constitutively expressed at high levels (Krone and Sass, 1994). It was shown by way of a morpholino-based knock-down approach that the $a$ form is involved in muscle development. It associates with Unc45b and together co-localize in the muscle close to the myosin filaments (Etard et al., 2007). Consistently with this localization, embryos in which hsp90a expression was chemically disrupted are paralyzed, that is, partially or totally incapable of moving (Lele et al., 1999; Etard et al., 2008). In addition, hsp90a has been connected with the apoptotic mechanism involved in lens degradation in another teleost, the blind cavefish (Hooven et al., 2004). hsp90bl is maternally expressed in the zebrafish and later, during development, is expressed in the floor plate, hatching gland, optic placode, and otic vesicle, in which it is involved in otolith formation (Sumanas et al., 2003).

TABLE 3. Examples of chaperonopathies due to mutations in the genes encoding chaperonins of Groups I and II

\begin{tabular}{ll}
\hline Gene/protein affected & Disease/syndrome \\
\hline $\begin{array}{l}\text { Chaperonin group I, Hsp60 } \\
\text { Mitochondrial Hsp60 (Cpn60) }\end{array}$ & Hereditary spastic paraplegia (SPG I3); MitCHAP-60 disease (Pelizaeus-Merzbacher-like) \\
$\begin{array}{l}\text { Chaperonin group II, CCT subunits } \\
\text { MKKS, BBSI0, and BBSI2 }\end{array}$ & $\begin{array}{l}\text { McKusick-Kaufman (MKKS); Bardet-Biedl (BBS) } \\
\text { CCT4, CCT5 }\end{array}$ \\
\hline
\end{tabular}

Modified from: Macario AJL, Conway de Macario E, Cappello F. 2013. The Chaperonopathies. Diseases with defective molecular chaperones. New York London: Springer Dordrecht Heidelberg. 
TABLE 4. Examples of chaperonopathies due to mutations in the $\mathrm{Hsp} 70$ and $\mathrm{Hsp} 40$ genes

\begin{tabular}{|c|c|}
\hline Gene/protein affected & Disease/syndrome \\
\hline \multicolumn{2}{|l|}{ Hsp70 } \\
\hline $\begin{array}{l}\text { STCH } \\
\text { mtHsp70 (HSPA9B; HSPA9) }\end{array}$ & $\begin{array}{l}\text { Stomach cancer } \\
\text { Parkinson's diseases; EVEN-PLUS syndrome }\end{array}$ \\
\hline \multicolumn{2}{|l|}{ Hsp40 } \\
\hline $\begin{array}{l}\text { DNAJB6 } \\
\text { HSJI } \\
\text { DNAJC6 }\end{array}$ & $\begin{array}{l}\text { Autosomal dominant limb-girdle muscular dystrophy (LGMD) with skeletal muscle vacuoles } \\
\text { Distal hereditary motor neuropathy } \\
\text { Juvenile Parkinsonism }\end{array}$ \\
\hline
\end{tabular}

Modified from: Macario AJL, Conway de Macario E, Cappello F. 2013. The Chaperonopathies. Diseases with defective molecular chaperones. New York London: Springer Dordrecht Heidelberg. For EVEN-PLUS syndrome, see Royer-Bertrand et al., 2015.

Despite its involvement in muscle and lens development and function, there is no clear evidence that Hsp90 is involved in genetic chaperonopathies, namely, no hsp 90 mutation has been found associated with any disease so far (Haslbeck et al., 20I2). This may be due to an important property suggested for Hsp90, that is, ability to buffer at the phenotypic level genetic mutations that, thus, become silent. For instance, it has been reported, that in Drosophila $\mathrm{Hsp} 90$ has the function of capacitor for morphological evolution thus playing a key role in the evolution of species (Rutherford and Lindquist, 1998). Hsp90 would function as a buffer mechanism, able to minimize or cancel at the phenotypic level the effect of genetic mutations. Therefore, genetic mutations may accumulate silent in the genome of a given population. Similar functions of $\mathrm{Hsp} 90$ have been proposed for other organisms, including zebrafish and other teleosts (Yeyati et al., 2007; Rohner et al., 20I3).

\section{Hsp70}

The human Hsp70 family is composed of at least 17 genes (Brocchieri et al., 2008). Most of these genes are present in zebrafish, but only few of them have been characterized. For instance, HspA8 is maternally expressed and accumulates also in the brain and somites (Santacruz et al., 1997; Yeh and Hsu, 2002). Four isoforms of Hsp70 are expressed in the lens, in which they attenuate apoptosis in post-mitotic lens fibers and are also involved in lens development, probably during the differentiation of post-mitotic lens fibers (Blechinger et al., 2002; Evans et al., 2005).

HspAI $2 b$ has been shown to be essential for the development of the vascular system and for endothelial cell migration (Hu et al., 2006). Consistent with these functions, HspAI $2 b$ is expressed in the ventral mesoderm territory, a precursor region of the hematopoietic/vascular system. $\mathrm{HspA} 9 \mathrm{~b}$ is important for the proper function of the hematopoietic system (Craven et al., 2005).

\section{Hsp40}

The Hsp40 family is large: in humans it is composed of at least 47 genes divided in three groups (DnaJa, DnaJb, and DnaJc) characterized by conserved domains in comparison with the reference $E$. coli Hsp40; an extensive comparison of these genes from coelacanth to human has recently been carried out (Tastan Bishop et al., 20l4). The common function of these Hsp genes is to serve as co-chaperones for Hsp70. $\mathrm{Hsp} 40$ proteins bind ribosomes and histones and recruit Hsp70 for the folding of nascent polypeptides (Huang et al., 2005). Examples of Hsp40 co-operation with Hsp70 are: (I) the close association to the ER translocon, allowing for the transport of proteins within the ER, again in concert with Hsp70 (Zimmermann and Blatch, 2009); and (2) involvement in endocytosis as they stimulate Hsp70 during the clathrinmediated endocytosis (Eisenberg and Greene, 2007).

However, more recent work has shown that they may have also independent functions: (I) protein degradation via interaction with the ubiquitin-proteasome system (Westhoff et al., 2005; Parfitt et al., 2009); (2) protein folding (Hageman et al., 20I0; Kampinga and Craig, 2010); (3) prevention of protein aggregation (Hageman et al., 2010; Kampinga and Craig, 2010); and (4) association with endosome membranes and participation in intracellular trafficking of growth factors (Girard et al., 2005).

Another Hsp40 is required for clathrin-mediated endocytosis during lung development in Drosophila and loss of this $\mathrm{Hsp} 40$ results in incomplete respiratory tube development and lack of clearance of airways (Behr et al., 2007).

In the zebrafish, an Hsp40 mutant (dnajb6b) has been identified via a transposon-mediated insertional mutagenesis screen (Ding et al., 2013). dnajb6b is expressed in the myocardium and co-localizes with actin in a striated arrangement, indicating that also in zebrafish, this Hsp40, like its human homolog (Sarparanta et al., 20I2), is localized to the muscle Z-disk. A second Hsp40, Dnaj-like, gene has been cloned in the zebrafish and it has been shown to be expressed in the central nervous system (CNS) and during caudal fin morphogenesis. Interestingly, this gene is neither induced by heat-shock nor by ethanol exposure, but its expression is specifically induced in all ray segments beneath the wound epidermis during caudal fin regeneration from $24 \mathrm{~h}$ post-amputation till 5 days post amputation (Tawk et al., 2000).

TABLE 5. Examples of chaperonopathies due to mutations in the sHsp

\begin{tabular}{ll}
\hline Gene/protein affected & \multicolumn{1}{c}{ Disease/syndrome } \\
\hline CRYAA (crystallin, alpha A) & Hereditary cataracts \\
CRYAB (crystallin alpha B) & Desmin-related myopathy with lens opacity \\
CRYAC (heat shock 22kDa protein 8) & Charcot-marie-tooth disease; distal hereditary motor neuropathies \\
HSPBI (heat shock 27kDa protein I) & Charcot-marie-tooth disease; distal hereditary motor neuropathies \\
HSPB6 (heat shock protein alpha-crystallin-related B6) & Dilated cardiomyopathy \\
\hline
\end{tabular}

Modified from: Macario AJL, Conway de Macario E, Cappello F. 2013. The Chaperonopathies. Diseases with defective molecular chaperones. New York London: Springer Dordrecht Heidelberg. 
TABLE 6. Hsp-chaperone genes in zebrafish as of November 20, 2015

\begin{tabular}{lcccc}
\hline Name & Genes & Mutants & Transcripts & Pseudogenes \\
\hline hsp & 97 & 44 & 61 & 0 \\
chaperone & 34 & 19 & 0 & 0 \\
cct & 10 & 7 & 8 & 0 \\
\hline
\end{tabular}

Source: http://zfin.org/; ZFIN: The Zebrafish Model Organism Database.

\section{sHsp}

The small heat shock protein family is composed of 10 genes in human and 13 in the zebrafish (Elicker and Hutson, 2007). All these small proteins present a conserved $\alpha$-crystallin domain of about 80 amino acids. Most of the sHSPs are expressed in the skeletal muscle. Some of these genes are heat inducible and the majority of them function as chaperones. However, other members of the sHSPs have different functions, like stabilization of actin filaments, regulation of cell motility and intermediate filaments assembly ( $\mathrm{HspBI} / \mathrm{Hsp} 27)$, maintaining the transparence of the lens ( $\alpha \mathrm{A}-\mathrm{Crystallin}$ and $\alpha \mathrm{B}$-crystallin). Relevant to this review are sHSP27 (hspbl gene) and sHSP22 (hspb8 gene) because both have been linked to human diseases determined by sHSPs malfunctions (see Table 5 , and its source).

Marvin et al. (2008) reported the expression pattern of all sHSP in the zebrafish from 10 hpf to two dpf. hspbl is ubiquitously expressed at $10 \mathrm{hpf}$, while at 24-48 hpf it was found expressed in lens, mid-hindbrain boundary, heart ocular muscle, differentiating jaw, muscle and notochord. From 10 to $48 \mathrm{hpf} h s p b 8$ was expressed in the notochord while it was transiently expressed in the ventral portion of the mid hindbrain boundary at $10 \mathrm{hpf}$ but not at later stages. Finally, hspb8 starts to be expressed in the somites from $24 \mathrm{hpf}$ onwards. hspb8 was also expressed in neurons in the lateral spinal cord, in the notochord, and probably the pronephric ducts at least till $2 \mathrm{dpf}$, that was the last stage analyzed (Marvin et al., 2008).

\section{Chaperonins}

This class of heat shock proteins is composed of two groups: Group I, including the mithocondrial Hsp60, and Group II, of which the typical example is the cytosolic chaperonin containing TCPI or CCT.

Humans have at least 14 cct genes, including canonical and non-canonical genes and one hsp60 gene (Mukherjee et al., 2010), many of which have counterparts in zebrafish. As mentioned earlier, the genomic data for $h s p 60$ and cct genes indicate that zebrafish would be amenable to modeling genetic chaperonopathies associated with alterations of these genes.

hsp60 is expressed both maternally and zygotically in the majority of tissues and its function has been linked to fin- and heart-tissue regeneration in the zebrafish. It is activated by stress and immune response after Aeromonas hydrophila infection in the grass carp (Xu et al., 20l I). cct3 is expressed ubiquitously starting from $12 \mathrm{~h}$ post fertilization and continues at later stages being particularly enriched in the CNS and somites (Matsuda and Mishina, 2004). cct5 is expressed ubiquitously in the zebrafish starting from $30 \%$ epiboly, and by 5 day post-fertilization its transcripts are enriched in the CNS and in the neuromasts (Rauch et al., 2003). cct8 is expressed in particular in the CNS at all stages analyzed ( $24 \mathrm{hpf}$ up $5 \mathrm{dpf}$ ) (Petzold et al., 2009).

\section{Zebrafish and Chaperone-Gene Mutations}

The research reviewed so far describes a scenario in which zebrafish and human heat shock proteins are highly conserved in sequence and function, suggesting that this non-mammalian vertebrate could be a powerful tool to study chaperonopathies. Indeed, zebrafish has been proposed as a model to study both genetic (Haslbeck et al., 20I2; Fink, 20I3) and acquired (Keller and Murtha, 2004) diseases due the chaperones malfunction. However, despite this positive starting point there are no reports that directly use the zebrafish model to study human chaperonopathies. Instead, in the few cases reported, hsp genes have been identified by means of forward genetics screens, that usually involve mutations presenting early stop codon or the insertion of a large reporter gene (GFP), or viral DNA (Matsuda and Mishina, 2004; Petzold et al., 2009; Ding et al., 2013).

Due to the very complex roles in cell and tissue homeostasis that Hsps play, these genes are highly conserved during evolution. Chaperone function involves the precise binding of other proteins, including other chaperons, and their interactive-cooperative activity can likely be disrupted by nullmutations. This could abolish the functionality of Hsps, a situation that may not be compatible with life. This is supported by the fact that the majority of Hsp mutations linked to a human pathology are missense mutations that probably reduce but do not abolish Hsp functions.

Two human mitochondrial Hsp70 (mit-Hsp70) variants (P509S and RI26W) have been found linked with Parkinson's disease (PD) (Goswami et al., 20I2). Changes in human Phe93Leu or Phe89lle in the ubiquitously expressed cochaperone DNAJB6 cause the autosomal dominant limb-girdle muscular dystrophy (LGMD) with skeletal muscle vacuoles (Sarparanta et al., 2012). Worth to notice, a dnajb6b mutation, induced by a transposon insertion and resulting in cardiac hypertrophy, has been recently identified in the zebrafish (Ding et al., 2013). The transposon insertion affects the splicing isoforms of Dnajb6b, it is a recessive mutation that dramatically reduces the normal splicing event between exon 6 and 7 and results into switching most Dnajb6b long isoform to Dnajb6b short-like isoform. At the subcellular level, zebrafish Dnajb6b appears to be expressed in the sarcomere and colocalized with the Actn2-EGFP, which was consistent with the Z-disc localization reported for DNAJB6(S) in human muscles (Ding et al., 20I3).

Hypomyelinating leukodystrophies (HMLs) and PelizaeusMerzbacher-like disease (PMLD) are disorders involving aberrant myelin formation that have been linked, respectively, to mutations in Proteolipid Protein I (PLPI), which encodes lipophilin, the most abundant myelin protein in the CNS (Garbern et al., 1999; Schiffmann and Boespflug-Tanguy, 200I), and to mutations in GJAI2, which encodes the gap junction protein connexin 47 (Cx47) (Uhlenberg et al., 2004; Bugiani et al., 2006). Two related syndromes have been linked to sHSPs misfunction, Distal Hereditary Motor Neuropathy end Charcot-Marie-Tooth disease. In both cases missense mutations targeting sHSP-27 in four different positions (three within the $\alpha$-crystallin domain transforming a polar residue into a hydrophobic amino acid) were discovered in affected families (Evgrafov et al., 2004). Two missense mutations of lysine $42 \mathrm{I}$ of sHSP22 have been linked to distal motor neuron neuropathy in a Belgian family and a Czech family (Irobi et al., 2004). Although, neither sHSP27 nor sHSP22 are expressed in motor neurons during zebrafish development (Marvin et al., 2008), it is yet not known if these genes are expressed in the adult motor neurons of the zebrafish, keeping open both possibilities that these sHSPs may work either cell-autonomously or non-cell autonomously. The zebrafish has been already proven to be a good model for Charcot-Marie-Tooth disease, by means of an ENU-induced nonsense mutation in zebrafish Mitofusin 2 (MNF2) (Lahvic et al., 20I3). MFN2 is a protein involved in the velocity and frequency of mitochondria retrograde movements, which in turn requires actin activity. Even though, 
direct correlations between sHSPs actin regulation and MFN2 mediated mitochondria retrograde movements has not been yet evaluated, this model provided further proofs of the value of the zebrafish for modeling human diseases. A missense mutation (D29G) in mithocondrial-Hsp60 causes MitCHAP-60 Disease (Magen et al., 2008). Hereditary spastic paraplegia (SPGI3) is an autosomal-recessive neurodegenerative disorder characterized by brain hypomyelination and leukodystrophy that is caused by a missense mutation V98I in Hsp60 (Hansen et al., 2002).

In the recent past, the genetic manipulations that were technically feasible in the zebrafish included random chemical mutagenesis, mostly using ENU (Mullins and NüssleinVolhard, 1993; Haffter et al., 1996), and viral and transposon based mutagenesis (Amsterdam et al., 1999; Kawakami et al., 2000; Balciunas et al., 2006). These techniques were instrumental for pursuing forward genetic studies, while the reverse genetic approach was feasible in part by the use of morpholino antisense oligonucleotides with transient knockdown of translation of a the target gene (Nasevicius and Ekker, 2000). While, the transient knock-down approach by morpholino antisense oligonucleotides did not lid to phenotypes related to chaperonopaties, the mutageneticbased technologies linked some Hsps with specific functions, for example: transposon insertion mutagenesis screen recently carried in the zebrafish revealed that a DNAJB6 protein, which has a GFP inserted in frame in its ORF, thus with reduced functionality, is associated with heart hypertrophy (Ding et al., 20I3). A point mutation (G $>A$ ) that produces a glycine-to-glutamate conversion at amino acid 492 in zebrafish HsA9b also dramatically affects mitochondrial functions and induces oxidative stress and blood cell death (Craven et al., 2005). This mutant (crimsonless) displays also erythroid dysplasia and multilineage cytopenia, all phenotypes that closely resemble in their complexity the Myelodysplastic Syndrome in humans. In this regard, it is pertinent to remark that of the many human 5qchromosome deletions causing such syndrome, the deletion involving a critical region in $5 q 31$ contains 9 genes, including that coding hspa9b (Horrigan et al., 2000).

In the zebrafish, three mutant forms of hsp60 (hspdl) have been identified: a transgenic insertion called la0269 I I Tg by the Burgess and Lin laboratories (Varshney et al., 20I3), and two ENU induced point mutations, sa I I I 57 (Busch-Nentwich et al., 20I3) and zp7 (Makino et al., 2005). Interestingly, this last mutant presents a missense mutation in V324E that is linked to a blastema phenotype resulting into a fin and hart regeneration defective zebrafish (Makino et al., 2005). Viral insertion in the zebrafish cct5 gene (cct5 $5^{\text {hi2972bTg }}$ ) shows at day 3 mild necrosis of the CNS and small head and eyes; while by day 5 they present in addition a pericardial edema and underdeveloped liver/gut (Amsterdam et al., 2004). In another forward genetic screen in the zebrafish, a mutation was uncovered, called bette davies (bdev), which shows insertion of their transposon, GBT-P9, in cct8 (Petzold et al., 2009). The resulting fish larvae presented a markedly reduced nicotine response profile. Interestingly, there is no such association between CCT8 and nicotine response in humans; one possible explanation for this difference is that the zebrafish phenotype was analyzed at the larval stage, and a second possibility is that CCT8 mutation, even though it is hypomorphic in the zebrafish, because they present a reduced but not absent levels of cct8, may not be a viable mutation in humans.

The phenotypes of these zebrafish Hsp mutants that show clear differences with the human counterparts are always presenting null or hypomorph mutations that may affect many of the functions of the Hsp, while the human mutations are missense mutations of amino acids that specifically affect only one of the many functions of the Hsp.
In the past 3 years, a simple yet powerful genome editing technology, using the CRISPR/Cas9 technique, has been developed, which made possible the targeting of specific regions in the genome of virtually all organisms in which it has been applied (Jao et al., 20 I 3; Dow, 20I5). This has allowed not only for the creation of mutants of target genes, but also for the reversion of mutations linked to diseases (Schwank et al., 20 I 3; Long et al., 20l4), the introduction of tags in frame to ORFs (Kimura et al., 20|4), and the precise modification of a wildtype gene into a specific mutant sequence (Matano et al., 20I5). This latest approach holds great promise to improve the use of the zebrafish as animal model for the study of chaperonopathies because it would allow the specific modification of one codon such to match exactly the missense mutation in human. Then, the very high degree of similarity between zebrafish and human Hsp sequences would support the idea that the same missense mutations would produce the same phenotypes, an encouraging hypothesis that should stimulate research.

\section{Acknowledgments}

G.B. and A.G. were supported by SHRO. A.J.L.M. and E.C.de M. were partially supported by IMET; A.J.L.M. and F.C. were partially supported by IEMEST. This work was done under the umbrella of the agreement between the Euro-Mediterranean Institute of Science and Technology (IEMEST, Italy) and the Institute of Marine and Environmental Technology (IMET, USA) signed in March 2012 (this is IMET contribution number IMET 16-172).

\section{Literature Cited}

Aguilà M, Bevilacqua D, McCulley C, Schwarz N, Athanasiou D, Kanuga N, Novoselov SS Lange CA, Ali RR, Bainbridge JW, Gias C, Coffey PJ, Garriga P, Cheetham ME. 20I4. Hsp90 inhibition protects against inherited retinal degeneration. Hum Mol Genet 23:2164-2175. Almeida MB, do Nascimento JL, Herculano AM, Crespo-López ME. 20II. Molecular chaperones: Toward new therapeutic tools. Biomed Pharmacother 65:239-243.

Amsterdam A, Burgess S, Golling G, Chen W, Sun Z, Townsend K, Farrington S, Haldi M, Hopkins N. 1999. A large-scale insertional mutagenesis screen in zebrafish. Genes Dev 13:2713-2724.

Amsterdam A, Nissen RM, Sun Z, Swindell EC, Farrington S, Hopkins N. 2004. Identification of 315 genes essential for early zebrafish development. Proc Natl Acad Sci 101:12792-12797.

Auer TO, Del Bene F. 2014. CRISPR/Cas9 and TALEN-mediated knock-in approaches in zebrafish. Methods 69:142-150.

Balciunas D, Wangensteen KJ, Wilber A, Bell J, Geurts A, Sivasubbu S, Wang X, Hackett PB, Largaespada DA, Mclvor RS, Ekker SC. 2006. Harnessing a high cargo-capacity transposon for genetic applications in vertebrates. PLoS Genet 2:el69.

Balciuniene J, Nagelberg D, Walsh KT, Camerota D, Georlette D, Biemar F, Bellipanni G, Balciunas D. 2013. Efficient disruption of zebrafish genes using a Gal4-containing gene trap. BMC Genomics 14:619.

Behr M, Wingen C, Wolf C, Schuh R, Hoch M. 2007. Wurst is essential for airway clearance and respiratory-tube size control. Nat Cell Biol 9:847-853.

Blechinger SR, Evans TG, Tang PT, Kuwada JY, Warren JT, Krone PH. 2002. The heatinducible zebrafish hsp70 gene is expressed during normal lens development under nonstress conditions. Mech Dev II2:213-215.

Bolshette NB, Thakur KK, Bidkar AP, Trandafir C, Kumar P, Gogoi R. 2014. Protein folding and misfolding in the neurodegenerative disorders: A review. Rev Neurol 170:15I-161.

Brocchieri L, Conway de Macario E, Macario AJL. 2008. Hsp-70 genes in the human genome: Conservation and differentiation patterns predict a wide array of overlapping and specialized functions. BMC Evol Biol 8:19.

Bugiani M, Al Shahwan S, Lamantea E, Bizzi A, Bakhsh E, Moroni I, Balestrini MR, Uziel G, Zeviani M. 2006. GJAI2 mutations in children with recessive hypomyelinating leukoencephalopathy. Neurology 67:273-279.

Busch-Nentwich E, Kettleborough R, Dooley CM, Scahill C, Sealy I, White R, Herd C, Mehroke S, Wali N, Carruthers S, Hall A, Collins J, Gibbons R, Pusztai Z, Clark R, Stemple DL. 2013. Sanger institute zebrafish mutation project mutant data submission. ZFIN direct data submission.

Cappello F, Conway de Macario E, Di Felice V, Zummo G, Macario AJL. 2009. Chlamydia trachomatis infection and anti-Hsp60 immunity: The two sides of the coin. PLoS Pathog 5: el000552.

Craven SE, French D, Ye W, de Sauvage F, Rosenthal A. 2005. Loss of Hspa9b in zebrafish recapitulates the ineffective hematopoiesis of the myelodysplastic syndrome. Blood 105:3528-3534.

Deture M, Hicks C, Petrucelli L. 2010. Targeting heat shock proteins in tauopathies. Curr Alzheimer Res 7:677-684.

Ding Y, Liu W, Deng Y, Jomok B, Yang J, Huang W, Clark KJ, Zhong TP, Lin X, Ekker SC, $X u X .2013$. Trapping cardiac recessive mutants via expression-based insertional mutagenesis screening. Circ Res II2:606-617.

Dow LE. 2015. Modeling disease in vivo With CRISPR/Cas9. Trends Mol Med 21:609-621.

Eisenberg E, Greene LE. 2007. Multiple roles of auxilin and Hsc70 in clathrin-mediated endocytosis. Traffic 8:640-646. 
Elicker KS, Hutson LD. 2007. Genome-wide analysis and expression profiling of the small heat shock proteins in zebrafish. Gene 403:60-69.

Ellis RJ. 1996. Discovery of molecular chaperones. Cell Stress Chaperones I:155-160.

Essig DA, Nosek TM. 1997. Muscle fatigue and induction of stress protein genes: A dual function of reactive oxygen species? Can J Appl Physiol 22:409-428.

Etard C, Behra M, Fischera N, Hutchesonb D, Geislerc R, Strähle U. 2007. The UCS factor Steif/Unc-45b interacts with the heat shock protein Hsp90a during myofibrillogenesis. Dev Biol 308:133-143.

Etard C, Roostalu U, Strähle U. 2008. Shuttling of the chaperones Unc45b and Hsp90a between the $A$ band and the $Z$ line of the myofibril. J Cell Biol 180:1163-1175.

Evans TG, Yamamoto Y, Jeffery WR, Krone PH. 2005. Zebrafish Hsp70 is required for embryonic lens formation. Cell Stress Chaperones 101:66-78.

Evgrafov OV, Mersiyanova I, Irobi J, Van Den Bosch L, Dierick I, Leung CL, Schagina O, Verpoorten N, Van Impe K, Fedotov V, Dadali E, Auer-Grumbach M, Windpassinger C Wagner K, Mitrovic Z, Hilton-Jones D, Talbot K, Martin JJ, Vasserman N, Tverskaya S. 2004. Mutant small heat-shock protein 27 causes axonal Charcot-Marie-Tooth disease and distal hereditary motor neuropathy. Nat Genet 36:602-606.

Fink JK. 2013. Hereditary spastic paraplegia: Clinico-pathologic features and emerging molecular mechanisms. Acta Neuropathol 126:307-328.

Garbern J, Cambi F, Shy M. 1999. The molecular pathogenesis of Pelizaeus-Merzbacher disease. Arch Neurol 56:1210-1214.

Gemberling M, Bailey TJ, Hyde DR, Poss KD. 2013. The zebrafish as a model for complex tissue regeneration. Trends Genet 29:6II-620.

Girard M, Poupon V, Blondeau F, McPhersons PS. 2005. The DnaJ-domain protein RME-8 functions in endosomal trafficking. J Biol Chem 280:40I35-40I43.

Goswami AV, Samaddar M, Sinha D, Purushotham J, D'Silva P. 2012. Enhanced J-protein interaction and compromised protein stability of $\mathrm{mtHsp} 70$ variants lead to mitochondria dysfunction in Parkinson's disease. Hum Mol Genet 21:3317-3332.

Grunwald DJ, Kimmel CB, Westerfield M, Walker C, Streisinger G. 1988. A neural degeneration mutation that spares primary neurons in the zebrafish. Dev Biol I:I115-128.

Haffter P, Granato M, Brand M, Mullins MC, Hammerschmidt M, Kane DA, Odenthal J, van Eeden FJ, Jiang YJ, Heisenberg CP, Kelsh RN, Furutani-Seiki M, Vogelsang E, Beuchle D, Schach U, Fabian C, Nüsslein-Volhard C. 1996. The identification of genes with unique and essential functions in the development of the zebrafish, Danio rerio. Development 123:1-36

Hageman J, Rujano MA, van Waarde MA, Kakkar V, Dirks RP, Govorukhina N, OosterveldHut HM, Lubsen NH, Kampinga HH. 2010. A DNAJB chaperone subfamily with HDAC dependent activities suppresses toxic protein aggregation. Mol Cell 37:355-369.

Hansen JJ, Dürr A, Cournu-Rebeix I, Georgopoulos C, Ang D, Nielsen MN, Davoine CS, Brice A, Fontaine B, Gregersen N, Bross P. 2002. Hereditary spastic paraplegia SPGI3 is associated with a mutation in the gene encoding the mitochondrial chaperonin $\mathrm{Hsp} 60$. Am J Hum Genet 70:1328-1332.

Haslbeck V, Kaiser C], Richter K. 2012 . Hsp90 in non-mammalian metazoan model systems. Biochim Biophys Acta |823:7|2-72|.

Higashijima S, Hotta $Y$, Okamoto H. 2000. Visualization of cranial motor neurons in live transgenic zebrafish expressing green fluorescent protein under the control of the islet-I promoter/enhancer. J Neurosci 20:206-218.

Hooven TA, Yamamoto Y, Jeffery WR. 2004. Blind cavefish and heat shock protein chaperones: A novel role for hsp90alpha in lens apoptosis. Int J Dev Biol 48:731-738.

Horrigan SK, Arbieva ZH, Xie HY, Kravarusic J, Fulton NC, Naik H, Le TT, Westbrook CA 2000. Delineation of a minimal interval and identification of 9 candidates for a tumor. Blood 95:2372-2377.

Howe K, Clark MD, Torroja CF, Torrance J, Berthelot C, Muffato M, Collins JE, Humphray S, McLaren K, Matthews L, McLaren S, Sealy I, Caccamo M, Churcher C, Scott C, Barrett JC, Koch R, Rauch GJ, White S, Chow W, Kilian B, Quintais LT, Guerra-Assunção JA, Zhou Y, Gu Y, Yen J, Vogel JH, Eyre T, Redmond S, Banerjee R, Chi J, Fu B, Langley E, Maguire SF Laird GK, Lloyd D, Kenyon E, Donaldson S, Sehra H, Almeida-King J, Loveland J, Trevanion S, Jones M, Quail M, Willey D, Hunt A, Burton J, Sims S, McLay K, Plumb B, Davis J. Clee C, Oliver K, Clark R, Riddle C, Elliot D, Threadgold G, Harden G, Ware D, Begum S, Mortimore B, Kerry G, Heath P, Phillimore B, Tracey A, Corby N, Dunn M, Johnson C, Wood J, Clark S, Pelan S, Griffiths G, Smith M, Glithero R, Howden P, Barker N, Lloyd C, Stevens C, Harley J, Holt K, Panagiotidis G, Lovell J, Beasley H, Henderson C, Gordon D, Auger K, Wright D, Collins J, Raisen C, Dyer L, Leung K, Robertson L, Ambridge K, Leongamornlert D, McGuire S, Gilderthorp R, Griffiths C, Manthravadi D, Nichol S, Barker G, Whitehead S, Kay M, Brown J, Murnane C, Gray E, Humphries M, Sycamore N, Barker D, Saunders D, Wallis J, Babbage A, Hammond S, Mashreghi-Mohammadi M, Barr L, Martin S, Wray P, Ellington A, Matthews N, Ellwood M, Woodmansey R, Clark G, Cooper J, Tromans A, Grafham D, Skuce C, Pandian R, Andrews R, Harrison E, Kimberley A, Garnett J, Fosker N, Hall R, Garner P, Kelly D, Bird C, Palmer S, Gehring I, Berger A, Dooley CM, Ersan-Ürün Z, Eser C, Geiger H, Geisler M, Karotki L, Kirn A, Konantz J, Konantz M, Oberländer M, Rudolph-Geiger S, Teucke M, Lanz C, Raddatz G, Osoegawa K, Zhu B, Rapp A, Widaa S, Langford C, Yang F, Schuster SC, Carter NP, Harrow J, Ning Z, Herrero ], Searle SM, Enright A, Geisler R, Plasterk RH, Lee C, Westerfield M, de Jong PJ, Zon LI, Postlethwait JH, NüssleinVolhard C, Hubbard TJ, Roest Crollius H, Rogers J, Stemple DL. 2013. The zebrafish reference genome sequence and its relationship to the human genome. Nature reference gen
$496: 498-503$.

Hu G, Tang J, Zhang B, Lin Y, Hanai J, Galloway J, Bedell V, Bahary N, Han Z, Ramchandran R, Thisse B, Thisse C, Zon LI, Sukhatme VP. 2006. A novel endothelial-specific heat shock protein $\mathrm{HspA}$ I2B is required in both zebrafish development and endothelial functions in vitro. J Cell Sci II 9:4II7-4I26.

Huang P, Gautschi M, Walter W, Rospert S, Craig EA. 2005. The Hsp70 SszI modulates the function of the ribosome-associated J-protein Zuol. Nat Struct Mol Biol 12:497-504.

Hwang WY, Fu Y, Reyon D, Maeder ML, Tsai SQ, Sander JD, Peterson RT, Yeh JR, Joung JK 2013. Efficient genome editing in zebrafish using a CRISPR-Cas system. Nat Biotechno $31: 227-229$

Irobi J, Van Impe K, Seeman P, Jordanova A, Dierick I, Verpoorten N, Michalik A, De Vriendt E, Jacobs A, Van Gerwen V, Vennekens K, Mazanec R, Tournev I, Hilton-Jones D, Talbot K, Kremensky I, Van Den Bosch L, Robberecht W, Van Vandekerckhove J, Van Broeckhoven C. 2004. Hot-spot residue in small heat-shock protein 22 causes distal motor neuropathy. Nat Genet 36:597-60I.

motor neuropathy. Nat Genet 36:597-601. CRISPR nuclease system. Proc Natl Acad Sci I 10:13904-13909.

Joly AL, Wettstein G, Mignot G, Ghiringhelli F, Garrido C. 2010. Dual role of heat shock proteins as regulators of apoptosis and innate immunity. J Innate Immun 2:238-247.

Kampinga HH, Craig EA. 2010. The HSP70 chaperone machinery: J proteins as drivers of functional specificity. Nat Rev Mol Cell Biol I I:579-592.
Kampinga HH, Hageman J, Vos MJ, Kubota H, Tanguay RM, Bruford EA, Cheetham ME, Chen B, Hightower LE. 2009. Guidelines for the nomenclature of the human heat shock proteins. Cell Stress Chaperones 14:105-111.

Kawakami K, Shima A, Kawakami N. 2000. Identification of a functional transposase of the Tol2 element, an Ac-like element from the Japanese medaka fish, and its transposition in the zebrafish germ lineage. Proc Natl Acad Sci 21: I | 403-I I 408.

Keller ET, Murtha JM. 2004. The use of mature zebrafish (Danio rerio) as a model for human aging and disease. Comp Biochem Physiol C Toxicol Pharmacol 138:335-34I.

Kikuchi K, Poss KD. 2012. Cardiac regenerative capacity and mechanisms. Annu Rev Cell Dev Biol 28:719-74I.

Kimura Y, Hisano Y, Kawahara A, Higashijima S. 2014. Efficient generation of knock-in transgenic zebrafish carrying reporter/driver genes by CRISPR/Cas9-mediated genome engineering. Sci Rep 4:6545.

Kinth P, Mahesh G, Panwar Y. 2013. Mapping of zebrafish research: A global outlook. Zebrafish 4:510-517.

Knowlton AA, Kapadia S, Torre-Amione G, Durand JB, Bies R, Young J, Mann DL. 1998. Differential expression of heat shock proteins in normal and failing human hearts. J Mol Cell Cardiol 30:811-818.

Kondoh Y, Osada H. 2013. High-throughput screening identifies small molecule inhibitors of molecular chaperones. Curr Pharm Des 19:473-492.

Krone PH, Sass JB. 1994. HSP 90 alpha and HSP 90 beta genes are present in the zebrafish and are differentially regulated in developing embryos. Biochem Biophys Res Commun 204:746-752.

Lahvic JL, Ji Y, Marin P, Zuflacht JP, Springel MW, Wosen JE, Davis L, Hutson LD, Amack JD, Marvin MJ. 20I3. Small heat shock proteins are necessary for heart migration and laterality determination in zebrafish. Dev Biol 384:166-180.

Lele Z, Hartson SD, Martin CC, Whitesell L, Matts RL, Krone PH. 1999. Disruption of zebrafish somite development by pharmacologic inhibition of Hsp90. Dev Biol $210: 56-70$.

Long C, McAnally JR, Shelton JM, Mireault AA, Bassel-Duby R, Olson EN. 2014. Prevention of muscular dystrophy in mice by CRISPR/Cas9-mediated editing of germline DNA. Science 345: I 184-1188.

Macario AJL, Cappello F, Zummo G, Conway de Macario E. 2010. Chaperonopathies of senescence and the scrambling of interactions between the chaperoning and the immune systems. Ann N Y Acad Sci I 197:85-93.

Macario AJL, Conway de Macario E. 2005. Sick chaperones, cellular stress, and disease. N Engl J Med 353:1489-150I.

Macario AJL, Conway de Macario E. 2007. Chaperonopathies and chaperonotherapy. FEBS Lett 581:368I-3688.

Macario AJL, Conway de Macario E, Cappello F. 2013. The Chaperonopathies. Diseases with defective molecular chaperones. New York, London: Springer Dordrecht Heidelberg, http://link.springer.com/book/10.1007\%2F978-94-007- 4667-I

Magen D, Georgopoulos C, Bross P, Ang D, Segev Y, Goldsher D, Nemirovski A, Shahar E, Ravid S, Luder A, Heno B, Gershoni-Baruch R, Skorecki K, Mandel H. 2008. Mitochondrial hsp60 chaperonopathy causes an autosomal-recessive neurodegenerative disorder linked to brain hypomyelination and leukodystrophy. Am J Hum Genet 83:30-42.

Makino S, Whitehead GG, Lien CL, Kim S, Jhawar P, Kono A, Kawata Y, Keating MT. 2005. Heat-shock protein 60 is required for blastema formation and maintenance during regeneration. Proc Natl Acad Sci 102:14599-14604.

Malafoglia V, Bryant B, Raffaeli W, Giordano A, Bellipanni G. 2013. The zebrafish as a model for nociception studies. I Cell Physiol 228:1956-1966.

Malafoglia V, Colasanti M, Raffaeli W, Balciunas D, Giordano A, Bellipanni G. 20I4. Extreme thermal noxious stimuli induce pain responses in zebrafish larvae. J Cell Physiol 229.300-308.

Marvin M, O'Rourke D, Kurihara T, Juliano CE, Harrison KL, Hutson LD. 2008. Developmental expression patterns of the zebrafish small heat shock proteins. Dev Dyn 237:454-463.

Matano M, Date S, Shimokawa M, Takano A, Fujii M, Ohta Y, Watanabe T, Kanai T, Sato T. 2015. Modeling colorectal cancer using CRISPR-Cas9-mediated engineering of human intestinal organoids. Nat Med 21:256-262

Matsuda N, Mishina M. 2004. Identification of chaperonin CCT gamma subunit as a determinant of retinotectal development by whole-genome subtraction cloning from zebrafish no tectal neuron mutant. Development |3|:|913-1925.

Min WK, Angileri F, Luo H, Lauria A, Shanmugasundaram M, Almerico AM, Cappello F, Conway de Macario E, Lednev IK, Macario AJL, Robb FT. 20I4. A human CCT5 gene mutation causing distal neuropathy impairs hexadecamer assembly in an archaeal model. Sci Rep (NATURE) 4:6688.

Mukherjee K, Conway de Macario E, Macario AJL, Brocchieri L. 20I0. Chaperonin genes on the rise: New divergent classes and intense duplication in human and other vertebrate genomes. BMC Evol Biol 10:64.

Mullins MC, Nüsslein-Volhard C. 1993. Mutational approaches to studying embryonic pattern formation in the zebrafish. Curr Opin Genet Dev 3:648-654.

Nasevicius A, Ekker SC. 2000. Effective targeted gene "knockdown" in zebrafish. Nat Genet 26:216-220.

Nicoli S, Ribatti D, Cotelli F, Presta M. 2007. Mammalian tumor xenografts induce neovascularization in zebrafish embryos. Cancer Res 67:2927-2931.

Parfitt DA, Michael GJ, Vermeulen EG, Prodromou NV, Webb TR, Gallo JM, Cheetham ME, Nicoll WS, Blatch GL, Chapple JP. 2009. The ataxia protein sacsin is a functional cochaperone that protects against polyglutamine-expanded ataxin-I. Hum Mol Genet 18:1556-1565.

Petzold AM, Balciunas D, Sivasubbu S, Clark KJ, Bedell VM, Westcot SE, Myers SR, Moulder GL, Thomas MJ, Ekker SC. 2009. Nicotine response genetics in the zebrafish. Proc Natl Acad Sci 106:18662-18667.

Rajaiah R, Moudgil KD. 2009. Heat-shock proteins can promote as well as regulate autoimmunity. Autoimmun Rev 8:388-393.

Rappa F, Farina F, Zummo G, David S, Campanella C, Carini F, Tomasello G, Damiani P, Cappello F, Conway De Macario E, Macario AJL. 2012. HSP-molecular chaperones in cancer biogenesis and tumor therapy: An overview. Anticancer Res 32.5139-5150.

Rauch G], Lyons DA, Middendorf I, Friedlander B, Arana N, Reyes T, Talbot WS. 2003. Submission and curation of gene expression data. https://zfin.org/ZDB-PUB-03 I 103-24. Reddy VS, Reddy GB. 2015. Emerging role for $\alpha$ B-crystallin as a therapeutic agent: Pros and cons. Curr Mol Med I5:47-6I.

Rohner N, Jarosz DF, Kowalko JE, Yoshizawa M, Jeffery WR, Borowsky RL, Lindquist S, Tabin CJ. 2013. Cryptic variation in morphological evolution: HSP90 as a capacitor for loss of eyes in cavefish. Science 342:1372-1375.

Royer-Bertrand B, Castillo-Taucher S, Moreno-Salinas R, Cho TJ, Chae JH, Choi M, Kim OH, Dikoglu E, Campos-Xavier B, Girardi E, Superti-Furga G, Bonafé L, Rivolta C, Unger S, 
Superti-Furga A. 2015. Mutations in the heat-shock protein A9 (HSPA9) gene cause the EVEN-PLUS syndrome of congenital malformations and skeletal dysplasia. Sci Rep 5:17154.

Rutherford SL, Lindquist S. 1998. Hsp90 as a capacitor for morphological evolution. Nature 396:336-342.

Santacruz H, Vriz S, Angelier N. 1997. Molecular characterization of a heat shock cognate cDNA of zebrafish, hsc70, and developmental expression of the corresponding transcripts. Dev Genet 21:223-233.

Sarparanta J, Jonson PH, Golzio C, Sandell S, Luque H, Screen M, McDonald K, Stajich JM, Mahjneh I, Vihola A, Raheem O, Penttilä S, Lehtinen S, Huovinen S, Palmio J, Tasca G, Ricci E, Hackman P, Hauser M, Katsanis N, Udd B. 20I2. Mutations affecting the cytoplasmic functions of the co-chaperone DNAJB6 cause limb-girdle muscular dystrophy. Nat Genet 44:450-455,SI-2.

Schiffmann R, Boespflug-Tanguy O. 200I. An update on the leukodystrophies. Curr Opin Neurol 14:789-794.

Schwank G, Koo BK, Sasselli V, Dekkers JF, Heo I, Demircan T, Sasaki N, Boymans S, Cuppen E, van der Ent CK, Nieuwenhuis EE, Beekman JM, Clevers H. 20I3. Functional repair of CFTR by CRISPR/Cas9 in intestinal stem cell organoids of cystic fibrosis patients. Cell Stem Cell 13:653-658.

Seth A, Stemple DL, Barroso I. 2013. The emerging use of zebrafish to model metabolic disease. Dis Model Mech 6:1080-1088.

Siekmann AF, Lawson ND. 2007. Notch signalling limits angiogenic cell behaviour in developing zebrafish arteries. Nature 445:78I-784

Singh IS, Hasday JD. 20I3. Fever, hyperthermia, and the heat shock response. Int J Hyperthermia 29:423-435.

Sumanas S, Larson JD, Miller Bever M. 2003. Zebrafish chaperone protein GP96 is required for otolith formation during ear development. Dev Biol 261:443-455.

Tastan Bishop O, Edkins AL, Blatch GL. 20I4. Sequence and domain conservation of the coelacanth $\mathrm{Hsp} 40$ and $\mathrm{Hsp} 90$ chaperones suggests conservation of function. Mol Dev Evol 322B:359-378.
Tawk M, Joulie C, Vriz S. 2000. Zebrafish Hsp40 and Hsc70 genes are both induced during caudal fin regeneration. Mech Dev 99:183-186.

Uhlenberg B, Schuelke M, Rüschendorf F, Ruf N, Kaindl AM, Henneke M, Thiele H, Stoltenburg-Didinger G, Aksu F, Topaloğlu H, Nürnberg P, Hübner C, Weschke B, Gärtner J. 2004. Mutations in the gene encoding gap junction protein alpha I 2 (connexin 46.6) cause Pelizaeus-Merzbacher-like disease. Am J Hum Genet 75:25I-260.

Varshney GK, Lu J, Gildea D, Huang H, Pei W, Yang Z, Huang SC, Schoenfeld DS, Pho N, Casero D, Hirase T, Mosbrook-Davis DM, Zhang S, Jao LE, Zhang B, Woods IG, Zimmerman S, Schier AF, Wolfsberg T, Pellegrini M, Burgess SM, Lin S. 201 3. A large-scale zebrafish gene knockout resource for the genome-wide study of gene function. Genome Res 23:727-735.

Wang G, Juang H, Dai R, Lee K, Lin S, Mivechi NF. 200I. Suppression of heat shock transcription factor HSFI in zebrafish causes heat-induced apoptosis. Genesis 30:195-197.

Westhoff B, Chapple JP, van der Spuy J, Hohfeld J, Cheetham ME. 2005. HSJI is a neuronal shuttling factor for the sorting of chaperone clients to the proteasome. Curr Biol 15:1058-1064

Wick G, Jakic B, Buszko M, Wick MC, Grundtman C. 2014. The role of heat shock proteins in atherosclerosis. Nat Rev Cardiol I I:516-529.

Xu XY, Shen YB, Fu JJ, Liu F, Guo SZ, Yang XM, Li JL. 20I I. Molecular cloning, characterization and expression patterns of HSP60 in the grass carp (Ctenopharyngodon idella). Fish Shellfish Immunol 31:864-870.

Yeh FL, Hsu T. 2002. Differential regulation of spontaneous and heat-induced HSP 70 expression in developing zebrafish (Danio rerio). J Exp Zool 293:349-359.

Yen J, White RM, Stemple DL. 2014. Zebrafish models of cancer: Progress and future challenges. Curr Opin Genet Dev 24:38-45.

Yeyati PL, Bancewicz RM, Maule J, van Heyningen V. 2007. Hsp90 selectively modulates phenotype in vertebrate development. PLoS Genet 3:e43.

Zimmermann R, Blatch GL. 2009. A novel twist to protein secretion in eukaryotes. Trends Parasitol 8:147-150. 